\title{
Transitional care to caregivers of dependent older people: an integrative literature review
}

\author{
Cuidado transicional aos cuidadores de idosos dependentes: revisão integrativa da literatura
}

Atención transicional a cuidadores de ancianos dependientes: revisión integrativa de la literatura

\section{Bruna Alexandra da Silva Ferreira ' ORCID: 0000-0002-3508-5871}

Thawanna Jeremias Barbosa Gomes" ORCID: 0000-0001-5943-627X

Cristina Rosa Soares Lavareda Baixinho" ORCID: 0000-0001-7417-1732

Óscar Manuel Ramos Ferreira" ORCID: 0000-0002-1703-347X

'Hospital Vila Franca de Xira. Vila Franca de Xira, Portugal. "Escola Superior de Enfermagem de Lisboa. Lisboa, Portugal.

How to cite this article: Ferreira BAIS, Gomes TJB, Baixinho CRSL, Ferreira OMR Transitional care to caregivers of dependent older people: an integrative literature review. Rev Bras Enferm. 2020;73(Suppl 3):e20200394. doi: http://dx.doi.org/10.1590/0034-7167-2020-0394

Corresponding author: Cristina Lavareda Baixinho E-mail: crbaixinho@esel.pt

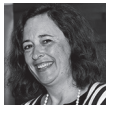

EDITOR IN CHIEF: Antonio José De Almeida Filho ASSOCIATE EDITOR: Fátima Helena Espírito Santo

Submission: 06-04-2020

Approval: 06-26-2020

\begin{abstract}
Objective: To identify the needs of caregivers of dependent older people related to self-care in the transition from hospital to home. Methods: Integrative literature review that followed a predefined protocol, carried out from March to May 2019 in the platforms EBSCO, B-On, Scopus, Web of Science, and Joanna Briggs Institute. Descriptors and eligibility criteria were defined for the bibliographic sample, which was ten articles. The search was limited to articles published between 2015 and 2019 to guarantee evidence topicality. Results: The needs of caregivers related to transitional care can be grouped into five categories: needs in the transition into the role of caregiver; needs related to self-care of caregivers themselves; health needs; economic needs; and social and collective needs. Final considerations: The work developed by nurses regarding transitional care of caregivers must have two focuses: managing care provided to dependent older people and managing the needs of caregivers and the care offered to them.

Descriptors: Transitional Care; Hospitalization; Caregivers; Elderly; Patient Discharge.
\end{abstract}

\section{RESUMO}

Objetivo: Identificar as necessidades dos cuidadores de idosos dependentes para o autocuidado na transição do hospital para casa. Métodos: Revisão integrativa que seguiu um protocolo pré-definido, realizada de março a maio de 2019, nas plataformas EBSCO, B-On, Scopus, Web of Science e Joanna Briggs Institute. Foram definidos descritores e critérios de elegibilidade para a amostra bibliográfica, que ficou constituída por dez artigos. Pela atualidade da evidência, limitou-se a pesquisa aos anos de 2015 a 2019. Resultados: As necessidades de cuidados transicionais para os cuidadores agrupam-se em cinco categorias: necessidades na transição para o papel de cuidador, necessidades de autocuidado dele próprio, necessidades de saúde, necessidades econômicas e necessidades sociais e comunitárias. Considerações finais: O cuidado transicional para os cuidadores deve ter dois focos de atenção, por parte dos enfermeiros: a gestão dos cuidados ao familiar dependente e a gestão das necessidades e dos cuidados ao próprio cuidador.

Descritores: Cuidado Transicional; Hospitalização; Cuidadores; Idoso; Alta do Paciente.

\section{RESUMEN}

Objetivo: Identificar las necesidades de los cuidadores de ancianos dependientes para el autocuidado en la transición del hospital al hogar. Método: Revisión integrativa, respetando un protocolo predefinido, realizada de marzo a mayo de 2019 en las plataformas EBSCO, B-On, Scopus, Web of Science y Joanna Briggs Institute. Fueron definidos descriptores y criterios de elegibilidad para la muestra bibliográfica, consistente en 10 artículos. Por la actualidad de la evidencia, la investigación se limitó al período 2015 a 2019. Resultados: Las necesidades de atención transicional para cuidadores se dividen en cinco categorías: necesidades en la transición al rol de cuidador; necesidades del propio autocuidado; necesidades de salud; necesidades económicas y necesidades sociales y comunitarias. Consideraciones finales: La atención transicional a los cuidadores debe tener dos focos de atención por parte de los enfermeros: la gestión de la atención al familiar dependiente y la gestión de las necesidades y atención del propio cuidador.

Descriptores: Cuidado de Transición; Hospitalización; Cuidadores; Anciano; Alta del Paciente. 


\section{INTRODUCTION}

The number of people 65 years old or older will increase from 524 million in 2010 to nearly 1.5 billion in $2050^{(1)}$. This change in the demographic profile of the population is followed by alterations in health-disease processes, in functioning, and in the quality of life of older people, including an increased incidence of chronic and/or disabling diseases, which lead to loss of independence ${ }^{(1)}$.

At present, 55\% of dependent older people show severe functional impairment, which requires the aid of a caregiver to support them in self-care and the execution of activities of daily living ${ }^{(2)}$. The dependence of these older people leads to some difficulties for caregivers, namely: the need for care, financial problems, changes in social life and resulting relationship issues, lack of family support, poor reaction to care, and lack of social resources ${ }^{(1-6)}$. Studies have shown that this new role has negative consequences such as anxiety, stress, exhaustion ${ }^{(1)}$, higher levels of depression, overload related to care, and lower levels of subjective well-being and perceived health ${ }^{(3)}$.

A study indicated that the changes in quality of life and health of caregivers may condition the provision of care to dependent relatives, with consequences such as insufficient functional improvement, unnecessary hospital readmissions, and long-lasting stays in long-term institutions for older people ${ }^{(4)}$. These problems point to the need for a special intervention by health professionals, mainly nurses, oriented toward caregivers, not just because of the transition they are about to experience into the new role they will take on, but also to allow the possibility of obtaining better health results for dependent older people ${ }^{(5)}$.

There is a consensus among researchers regarding the introduction of instruments that assess caregivers' needs $s^{(5-6)}$, to individualize the intervention proposed to people that provide care to dependent older people ${ }^{(6)}$. However, the literature indicates that the objective of interventions oriented toward caregivers is training them or relieving the emotional overload they experience, so they can replace or help dependent older people in the execution of activities of daily living and manage the therapeutic regimen, especially the adequate and safe medication administration ${ }^{(4-14)}$.

Another point is that most studies focus attention on caregivers in two strict contexts, hospital or community, without discussing care continuity related to the transition into the role of caregiver. Even studies on care continuity lack information about what the needs related to transitional care to caregivers are, which allows to corroborate the statement that the focus of interventions remains on older people, although it is known that caregivers are crucial in the process of transition to the home environment ${ }^{(12)}$. To change this situation, it is necessary that the focus of the planning of hospital discharge and return to home includes caregivers and the evaluation of their needs, to guarantee a safe transition from hospital to community for both dependent older people and caregivers ${ }^{(15-16)}$.

People admitted to hospitals are vulnerable to experiencing care continuity loss when there are alterations in their health condition or when they are transferred between care institutions ${ }^{(16)}$. This poses a remarkable challenge for health systems to guarantee the execution of a set of actions whose objective is ensuring care continuity between different care levels ${ }^{(17)}$, which helps in the process of adapting to the new care reality ${ }^{(15-17)}$. Additionally, care continuity contributes to decreasing costs and is an adequate strategy and a policy to be replicated by health services ${ }^{(16)}$.

An integrative literature review (ILR) that had the objective of identifying evidence about hospital transition care provided to older people in scientific production showed that this type of care benefits both older people with complex chronic and therapeutic conditions and their caregivers, who often become vulnerable to experiencing derangements or making mistakes when providing care because of lack of guidance. However, the study emphasized that this type of care is relatively uncommon and that a limited number of older people can benefit from its advantages ${ }^{(17)}$.

The present ILR was carried out to identify caregivers' needs when the transition from hospital to home occurs, with the objective of contributing to the public discussion on transitional care provided to caregivers of dependent older people.

\section{OBJECTIVE}

To identify the needs of caregivers of dependent older people related to self-care in the transition from hospital to home.

\section{METHODS}

\section{Ethical aspects}

This was a secondary study to which a report was not requested to the ethics commission. The researchers observed integrity principles when performing the study. Formulation of the study problem took into account the principles of clarity, accuracy, objectivity, and delimitation, allowing that its results can contribute to solving a prevailing problem in health care and bringing benefits to caregivers. Rigor in the different methodological procedures was guaranteed to ensure the study validity. Extraction and analysis of data reported in the primary studies that made up the bibliographic sample were carried out with express respect for research and the results obtained by other researchers. Referencing of the authors who supported the elaboration of the present study followed the recommendations of good academic and scientific practices.

\section{Study type}

Considering the state of the art and the nature of the phenomenon under discussion, the authors opted to carry out an ILR, to allow knowledge synthesis and incorporation of the relevant results into practice. A predefined protocol containing six steps was followed: (1) identification of the subject and selection of the hypothesis or research question; (2) establishment of study inclusion and exclusion criteria; (3) definition of the information to be extracted; (4) evaluation of the included articles; (5) interpretation of results; and (6) presentation of knowledge review/synthesis ${ }^{(18)}$.

\section{Methodological procedures}

The question formulated according to the PICo mnemonic (population, phenomenon of interest, and context) that guided 
the present ILR was: What are the needs of caregivers of dependent older people when the transition from hospital to home occurs?

Inclusion and exclusion criteria were defined for the studies found in the searched databases (Chart 1).

Chart 1 - Study eligibility criteria, Lisbon; Portugal, 2019

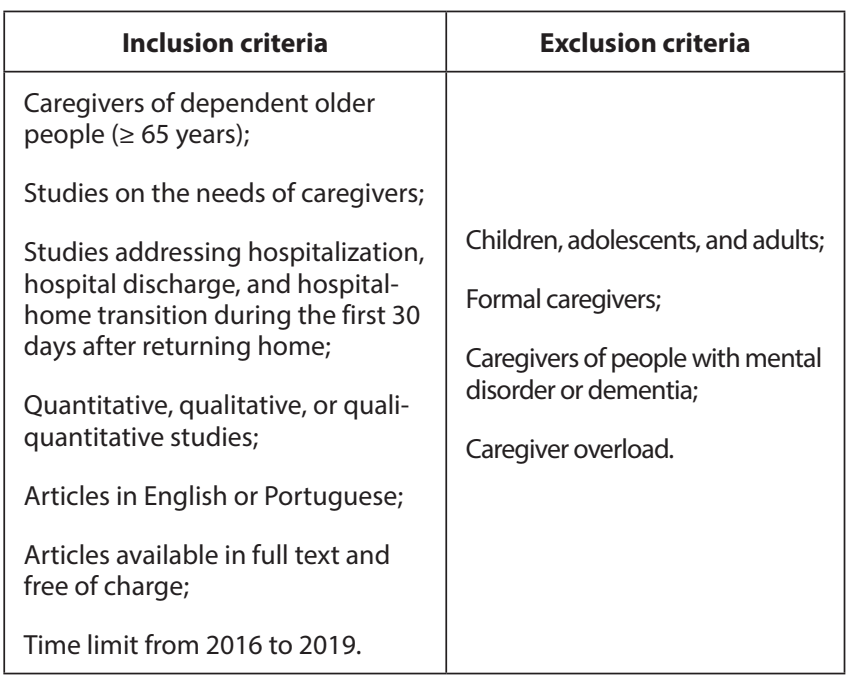

The criterion related to the establishment of a time limit from 2016 to 2019 was defined to guarantee information topicality.

The option of including studies that evaluated the need of caregivers in different care phases (hospitalization, hospital discharge, hospital-home transition, and the first 30 days after returning home) was justified by the recommendations that advocate that the interventions to manage the transition from hospital to home happen in three different steps: before the patient leaves hospital, during hospital discharge, and between 48 hours and 30 days after discharge ${ }^{(17,19)}$.

To be included in the sample, the literature review studies had to contain at least one study addressing one of these phases in their sample, and their results had to allow the identification of the needs of informal caregivers during the transition from hospital to home.

\section{Data collection and organization}

The present study was carried out between March to May 2019 in the databases available in the platforms EBSCO, B-On, Scopus, Web of Science, and Joanna Briggs Institute. The used descriptors, extracted from Medical Subject Headings, were associated by using the Boolean operators "AND" and "OR": ("elderly" or "older people" or "aged") and ("caregiver" or "family caregivers" or "family") and ("dependence" or "hospitalization"or"needs assessment"or"frail elderly") and ("discharge" or "from hospital to home" or "transitional care model").

The search resulted in 1,210 articles. Article identification, evaluation, and selection were carried out by two researchers independently, and a consensus was reached. After exclusion of duplicates and reading of titles and abstracts, 46 articles were selected for full-text reading (Figure 1). In this phase, six studies were excluded, because the examined population was older people with dementia. Other 23 studies were eliminated from the sample because they lacked information on the phase in which data collection was performed. One ILR was excluded because one of its inclusion criteria was caregivers of people 18 years old or older. Last, six articles were eliminated from the sample because they did not answer the research question of the present review.

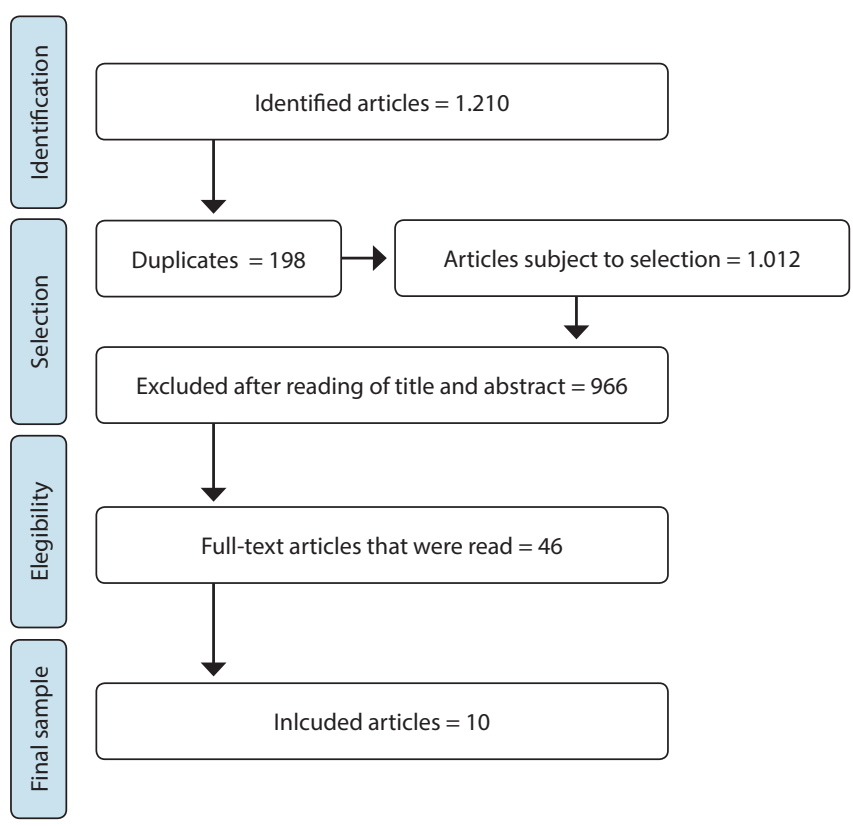

Figure 1 - Flowchart showing the article selection process, Lisbon, Portugal, 2019

\section{Data analysis}

The researchers designed a table on Microsoft Excel to register the content extracted from the articles that made up the final bibliographic sample. This table contained the following columns: identification of the article/work title; author(s), publication year, and article type; objective(s) and method(s); and level of evidence and main results/conclusions.

The results that answered the research question were extracted and submitted to thematic content analysis as proposed by Bar$\operatorname{din}^{(20)}$. Representativeness, exhaustiveness, homogeneity, and pertinence to the object of the present study were guaranteed when categories were defined. Two researchers carried out the codification and the other researchers assessed it to increase the reliability of the present study.

\section{RESULTS}

The ten selected studies (S) (Chart 2) made up a sample that was not homogeneous. They had different objectives and designs, which hindered results comparison. Half the sample were literature reviews with scientific methodology ${ }^{(21-25)}$. The primary studies had qualitative ${ }^{(2,12,26)}$, quantitative ${ }^{(9)}$, and quali-quantitative approaches ${ }^{(11)}$. Interpreting the information found in these sources allowed to answer the research question, despite the differences between them, including the different methodologies they applied.

The selected articles were published from 2016 to 2019 [2016 (1S), 2017 (4S), 2018 (5S)]. There was a marked geographic disparity in study distribution: three studies were Australian ${ }^{(9,21,26)}$, three were Brazilian ${ }^{(11,22-23)}$, two were carried out in the United Kingdom $^{(12,25)}$, one in Portugal ${ }^{(24)}$, and one in Philippines ${ }^{(2)}$. 
Chart 2 - Studies that made up the bibliographic sample, Lisbon, Portugal, 2019

\begin{tabular}{|c|c|c|c|c|}
\hline Reference & $\begin{array}{l}\text { Year } \\
\text { Country }\end{array}$ & $\begin{array}{l}\text { Study type } \\
\text { Sample }\end{array}$ & Objective & Outcomes \\
\hline$S 1^{(21)}$ & $\begin{array}{c}2017 \\
\text { Australia }\end{array}$ & $\begin{array}{l}\text { Metasynthesis } \\
20 \text { studies }\end{array}$ & $\begin{array}{l}\text { To improve the understanding of the } \\
\text { experience of older people and caregivers, } \\
\text { as well as of care integration in the } \\
\text { hospital-home transition. }\end{array}$ & $\begin{array}{l}\text { Information and search for information-related needs, } \\
\text { integration of transitional care, and improvement of } \\
\text { the transition experience. }\end{array}$ \\
\hline $\mathrm{S} 2^{(22)}$ & $\begin{array}{l}2018 \\
\text { Brazil }\end{array}$ & $\begin{array}{c}\text { ILR } \\
9 \text { articles }\end{array}$ & $\begin{array}{l}\text { To analyze the Brazilian literature on } \\
\text { depression in caregivers of older people. }\end{array}$ & $\begin{array}{l}\text { There were social support needs. This can originate a } \\
\text { network that can help create mechanisms to reduce } \\
\text { the impact of depression and improve the mental well- } \\
\text { being of caregivers. }\end{array}$ \\
\hline $\mathrm{S} 3^{(23)}$ & $\begin{array}{l}2016 \\
\text { Brazil }\end{array}$ & $\begin{array}{c}\text { ILR } \\
11 \text { articles }\end{array}$ & $\begin{array}{l}\text { To identify the main needs expressed by } \\
\text { caregivers regarding care provided to } \\
\text { dependent people. }\end{array}$ & $\begin{array}{l}\text { Need for knowledge and learning; need for time } \\
\text { to carry out a variety of activities; emotional and } \\
\text { interpersonal needs; social needs, support network } \\
\text { for caregivers, financial and structural support; and } \\
\text { information and communication. }\end{array}$ \\
\hline$S 4^{(24)}$ & $\begin{array}{c}2017 \\
\text { Portugal }\end{array}$ & $\begin{array}{c}\text { ILR } \\
11 \text { articles }\end{array}$ & $\begin{array}{l}\text { To identify information needs of } \\
\text { caregivers of dependent people. }\end{array}$ & $\begin{array}{l}\text { Information needs of caregivers could be grouped into } \\
\text { three main themes: } 1 \text { ) knowledge and skills of caregivers; } \\
\text { 2) potential resources for caregivers; and 3) well-being } \\
\text { and coping strategies of caregivers. }\end{array}$ \\
\hline $\mathrm{S} 5^{(25)}$ & $\begin{array}{l}2018 \\
\text { United } \\
\text { Kingdom }\end{array}$ & $\begin{array}{l}\text { Systematic review with } \\
\text { meta-ethnography } \\
51 \text { articles }\end{array}$ & $\begin{array}{l}\text { To describe and explain the experiences } \\
\text { of cerebrovascular accident survivors } \\
\text { and their informal caregivers. }\end{array}$ & $\begin{array}{l}\text { Needs related to care continuity, access to services, } \\
\text { and information and education. }\end{array}$ \\
\hline $\mathrm{S} 6^{(2)}$ & $\begin{array}{l}2017 \\
\text { Philippines }\end{array}$ & $\begin{array}{l}\text { Qualitative } \\
65 \text { caregivers }\end{array}$ & $\begin{array}{l}\text { To identify and evaluate the learning } \\
\text { and high-quality care needs of family } \\
\text { caregivers of older people. }\end{array}$ & $\begin{array}{l}\text { Caregivers had learning needs regarding: medical } \\
\text { conditions of older people; medication administration; } \\
\text { precautions that must be considered concerning } \\
\text { techniques, diet, and nutrition; walking techniques } \\
\text { and strategies; financial support; peer support; and } \\
\text { family management. }\end{array}$ \\
\hline$S 7^{(26)}$ & $\begin{array}{c}2018 \\
\text { Australia }\end{array}$ & $\begin{array}{l}\text { Qualitative } \\
19 \text { dependent people } \\
\text { and } 7 \text { informal } \\
\text { caregivers }\end{array}$ & $\begin{array}{l}\text { To report the experience of caregivers } \\
\text { and sick older people. }\end{array}$ & $\begin{array}{l}\text { Support needs; needs related to care provided by } \\
\text { health professionals; search for information; discussing } \\
\text { and negotiating the transitional care plan; and learning } \\
\text { needs related to self-care. }\end{array}$ \\
\hline $\mathrm{S} 8^{(12)}$ & $\begin{array}{l}2018 \\
\text { United } \\
\text { Kingdom }\end{array}$ & $\begin{array}{l}\text { Qualitative } \\
40 \text { health professionals } \\
\text { and } 22 \text { caregivers }\end{array}$ & $\begin{array}{l}\text { To explore whether and how caregivers are } \\
\text { supported when hospital discharge occurs; } \\
\text { and to evaluate perceived benefits and the } \\
\text { acceptability and applicability of the Carer } \\
\text { Support Needs Assessment Tool. }\end{array}$ & $\begin{array}{l}\text { Communication, support, and psychoemotional needs, } \\
\text { and needs related to the evaluation of their own } \\
\text { requirements and not only of those of the sick people } \\
\text { they cared for. }\end{array}$ \\
\hline $\mathrm{S} 9^{(9)}$ & $\begin{array}{c}2018 \\
\text { Australia }\end{array}$ & $\begin{array}{l}\text { Randomized study } \\
64 \text { caregivers }\end{array}$ & $\begin{array}{l}\text { To describe a new approach to identify } \\
\text { and address the needs of caregivers of } \\
\text { older people after hospital discharge. }\end{array}$ & $\begin{array}{l}\text { The three main support needs identified by caregivers } \\
\text { were: knowing what to expect in the future, knowing } \\
\text { who to contact, and practical support at home. }\end{array}$ \\
\hline $\mathrm{S} 10^{(11)}$ & $\begin{array}{l}2017 \\
\text { Brazil }\end{array}$ & $\begin{array}{l}\text { Quali-quantitative } \\
\text { exploratory study } \\
55 \text { caregivers }\end{array}$ & $\begin{array}{l}\text { To identify the perceived and standard } \\
\text { needs of main caregivers related to the } \\
\text { instrumental support to older people. }\end{array}$ & $\begin{array}{l}\text { The perceived needs were related to information on } \\
\text { instrumental support activities (bed bath and shower } \\
\text { bath; dressing dependent people; diaper change; and } \\
\text { precautions related to medications) and subjective } \\
\text { aspects of care. Caregivers showed a higher number } \\
\text { of standard needs related to precautions regarding } \\
\text { medication administration. }\end{array}$ \\
\hline
\end{tabular}

Analysis of the articles' content allowed to group the needs of caregivers into five categories: needs related to the transition into the role of caregiver; caregivers' self-care needs; health needs; economic needs; and social and community needs.

\section{Needs related to the transition into the role of caregiver}

Providing care informally implies considerable changes in individual and family life, along with the indispensable need to acquire new knowledge and competences so caregivers can safely meet older people's needs and experience a successful transition into the new role they have to take on. Consequently, a series of needs related to this transition emerges.

Three subcategories could be identified in this group: 1) information; 2) mastery of care; and 3) emotional support and overload prevention.

Regarding information in the transition into the role of caregiver, it is imperative that caregivers acquire new knowledge and skills $^{(2,9,11-12,21,23-26)}$ related to self-care and care provided at home ${ }^{(11,23)}$, so they can play their role with autonomy and safety and carry 
out activities of daily living, namely mobilization, transfer, bed bath, shower bath, dressing dependent people, diaper change, and precautions related to medication administration ${ }^{(2,11)}$. S2 showed that learning needs were related to understanding the nature of the disease and the medical condition itself, which encompassed medication administration, techniques to provide care, diet and nutrition, walking techniques and strategies, knowledge regarding financial support, and the global management of care $^{(2)}$. Specific questions related to the dependent older people's current situation were raised, for instance how to deal with and feed people with a nasogastric tube or percutaneous endoscopic gastrostomy ${ }^{(2)}$, management of medical appointments and tests, and those related to diagnosis and symptoms management ${ }^{(9)}$.

The transition into the role of caregiver requires mastering a set of technical skills and competences that allow to provide dependent older people with high-quality care $^{(23)}$. In S8 and S9, the authors advocated that it is important that caregivers acquire technical skills and competences that prepare them to offer high-quality care ${ }^{(23-24)}$. To accomplish this goal, health professionals must offer caregivers training on providing specific care such as procedures related to feeding, personal hygiene, mobilization, and dressing dependent people ${ }^{(23)}$. The authors of 59 added the need to train caregivers for them to develop skills that allow to carry out their role effectively, because they do not always feel able to offer the care necessary to meet older people's needs, from changing diapers to controlling symptoms by using medication ${ }^{(24)}$.

Regarding emotional support and overload prevention, analysis of the articles' content showed that caregivers need to know who they should contact in case of difficulty or crisis, as well as what to expect concerning the future evolution of the dependent older person's health condition ${ }^{(9)}$. In S8, the authors identified a certain set of emotional needs, including: need to have support to keep hope in the future; being encouraged to ask other people for help; expressing their feelings for the older person or caregiving to someone who has been through the same experience; having someone who understands how difficult playing the caregiver role is; having support regarding questions and fears related to the future; having time for their spirituality, namely going to church or temple and discussing feelings for the sick person (strong negative feelings such as anxiety); and keeping long-term relationships ${ }^{(23)}$.

These support needs also encompassed the need for family support, participating in psychoemotional support groups, and getting help to develop coping strategies to deal with problems $^{(9,23-24)}$.

\section{Caregivers' self-care needs}

This category covered the self-care needs of caregivers themselves and the harmonization of the new role with the management of the family dynamics, the keeping of other roles, and social relationships ${ }^{(11-12,23)}$. Although this harmonization was not deeply explored in S8, the authors of this study warned that not balancing the different roles can lead to tension and conflict ${ }^{(23)}$. Caregivers need to have time for themselves, to sleep, to be with their relatives and friends, and to go to $\operatorname{church}^{(23)}$.

\section{Health needs}

Preparing hospital discharge of dependent older people focuses on the concern with the self-care and health needs of these people, and people who are about to become caregivers are seen as a resource to carry out care continuity. However, this situational transition into the role of caregiver can occur simultaneously to hospital discharge or even trigger health-disease transitions ${ }^{(12)}$. In S2, caregivers expressed that they had negative experiences such as emotional crisis, physical discomfort, including fatigue and exhaustion, feelings of fear and anxiety, social isolation, depression, and despondency ${ }^{(2)}$, which may lead to situations of physical and/or mental disease.

\section{Economic needs}

S3, S8, and S9 found that caregiving implied financial expenses to obtain material and human resources ${ }^{(11,23-24)}$. Some caregivers, in addition to having opted to give up work, a decision that results in financial loss itself, needed to purchase support products that would help them provide care to dependent older people.

According to the authors of $\mathrm{S} 8$, most caregivers need financial support because they do not have economic resources to buy the materials necessary for caregiving, and they often need support to adapt the facilities/buildings when there are architectural barriers $^{(23)}$. As a considerable share of the examined caregivers had to give up work to provide care or were retired people, financial needs were a constant concern ${ }^{(24)}$.

\section{Social and community needs}

The last category referred to the social and community needs experienced by caregivers. To guarantee high-quality informal caregiving and a smooth transition into the role of caregiver, it is important that people can draw on some social and community resources ${ }^{(9,11,23-24)}$. Consequently, it is necessary to pay attention to the needs related to help with transportation and special equipment that is necessary to meet the physical needs of dependent older people, and rest-related needs of caregivers and knowledge of the resources that allow them to enjoy it ${ }^{(23)}$. Even with the presence of a caregiver at home, there might be the need for home support services that help provide home care ${ }^{(9,11,24)}$, especially in situations that involve higher complexity and vulnerability of older people or family members.

This type of need reinforces the importance of caregivers' having adequate information on social and community resources that are available and may help their specific cases, namely support services, public, private, and social support institutions, and teams of professionals to help with home care ${ }^{(24)}$.

\section{DISCUSSION}

The five categories that emerged from content analysis applied to the articles that made up the sample indicated that caregivers have a set of complex and interconnected needs when they experienced the transition into this new role, which poses a challenge to transitional care. The situation is even more difficult because 
organizations remain centered at sick people's needs rather than caregivers $^{\prime(12)}$, and the clinical approach of professionals during the planning process is oriented to the former and the changes that dependence brings to their self-care. In this scenario, caregivers are seen as a resource to solve the problem ${ }^{(12,15)}$ instead of care receivers.

A ILR that was excluded from the sample for not meeting one of the predefined eligibility criteria (it examined caregivers of people 18 years old or older) identified a set of needs of caregivers of dependent people that included: need for knowledge and learning; need for time to carry out varied activities; emotional and interpersonal needs; social needs, support network for caregivers, financial and structural support; information and communication $^{(1)}$.

It is undisputed that health-disease transitions that originate dependence and do not allow functional recovery to prehospitalization levels imply comprehensive adaptation, of the patient to their new dependence situation and of the family, to guarantee self-care after their return home. In the first phase, the concerns focus on the needs related to the transition into the role of caregiver.

The results of the present review identified three subcategories related to the need for information, mastering care, and emotional support and overload prevention, which corroborated the conclusions of other studies ${ }^{(1,15-16,27-30)}$. Caregivers need information on the disease, medication, symptoms management, activities they can carry out safely, recovery strategies ${ }^{(15-16,27)}$, disease prognosis, impact, and complications, treatments, predicted scenario after hospitalization, existing options ${ }^{(28)}$, and available resources ${ }^{(30)}$.

It is important to emphasize that learning needs related to hospital discharge emerge in the initial phase of hospitalization $^{(15,28)}$. For caregivers to have proper answers, written material about the transmitted information must be arranged for, because it favors learning and allows caregivers to review the addressed contents ${ }^{(8)}$. A study associated having information with having motivation to provide care ${ }^{(31)}$.

When taking on their new role, caregivers guarantee the existence of a set of special care situations and of answers to behavioral problems shown by dependent older people. To be able to do that, they have to gain expertise ${ }^{(15,30)}$. They have to train still in the hospitalization phase to develop skills that allow them to effectively play the caregiver role ${ }^{(24,32)}$. Even activities that seem simple to health professionals, such as hygiene care procedures or a diaper change, must be learned ${ }^{(24)}$.

Emotional support was probably the intervention that was most cited in the literature as being a priority for caregivers, given that its absence can hinder adaptation to the new role and contribute to an increased overload, reduced well-being, and worse health in this population. These problems can lead to a decrease in the quality of care provided to dependent older people $e^{(24-25,30-34)}$.

The findings of the present ILR were corroborated by another study that mentioned the need for families to offer emotional support to caregivers, the need to be acknowledged by other people (especially the dependent older person), and the importance of being satisfied with caregiving and of the use of effective coping strategies that allow to deal with the disease and manage stress and the feelings stirred by caregiving ${ }^{(30)}$.
It was observed that caregivers often encounter difficulties to carry out their self-care ${ }^{(11-12,23)}$. Other authors warned that the difficulties are mostly resting and sleeping, because of the efforts involved in caregiving, and managing time to take care of themselves, keep interpersonal relationships, have spare time to enjoy leisure activities, and have social life ${ }^{(30)}$. This finding is doubly worrying, because of the negative influence on both caregivers health and the quality of care they provide $\mathrm{e}^{(8,30-32)}$.

It is imperative that nurses reinforce to caregivers the idea that making time for themselves is a necessity, so they can enjoy other aspects of life, such as marriage and children. It is also fundamental that health professionals teach caregivers strategies that allow them to achieve this goal ${ }^{(23,30)}$.

Health needs of caregivers require special interventions by health systems. This population must be seen not only as partners, but also as a target for nursing interventions. It is important to mention that most caregivers are women, with an average age higher than 65 years and showing their own chronic diseases, which must be managed along with care provided to dependent older people and their disease ${ }^{(34)}$.

Caregiving implies continuous efforts at the physical, cognitive, and emotional levels. Consequently, it is commonly associated with an increase in the incidence of some diseases ${ }^{(32)}$, including pain that affects activities of daily living, leading to increased consumption of medication ${ }^{(34)}$. Stress, depression, and anxiety resulting from providing care to older people on a daily basis can also contribute to deteriorating caregivers' health and well-being ${ }^{(3)}$.

Economic, social, and community needs identified in content analysis corroborated results reported in other studies describing the need to give up work, retire, and purchase products as causes of financial overload ${ }^{(1,32)}$. In addition to the needs related to economic support, caregivers pointed that having flexible working hours to be able to balance caregiving with their professional activity was also a need ${ }^{(32)}$.

It is a consensus that it might be necessary to resort to some social and community resources, have accessibility to health care guaranteed ${ }^{(32)}$, and receive support from health teams to offer high-quality informal caregiving and ensure a good transition into the role of caregiver ${ }^{(15-16,23,30,32)}$. This is why even before hospital discharge caregivers must receive information on social and community resources that are available and can be useful for their specific case, especially support services, public, private, and social support institutions, and teams of professionals who can help in home care ${ }^{(24)}$.

The final bibliographic sample of the present ILR was heterogeneous. It included literature reviews with scientific methodology and primary studies, with the latter showing qualitative ${ }^{(2,12,26)}$, quantitative $^{(9)}$, and quali-quantitative approaches ${ }^{(11)}$, which hindered comparison of the studies. However, the convergence between primary and secondary studies and between qualitative findings and quantitative data offered the advantage of allowing a deep understanding of the complexity of the phenomenon under discussion and a more comprehensive answer to the guiding question that oriented the present review.

The authors end this discussion by observing that there are many studies on caregivers, but few have addressed their real needs and the interventions of health professionals, especially nurses, in the 
field of transitional care, considering caregivers as both care agents (when the transition into the caregiver role occurs) and people who have their own self-care and health needs. Not every study mentioned the phase in which data collection was carried out, which hindered the identification of the period between hospital discharge and the time caregivers were evaluated.

\section{Study limitations}

The limitations of the present review resulted from the heterogeneity of the studies that made up the sample and the different methods used by them. Only studies in English, Spanish, and Portuguese were included. Excluding studies published in other languages and gray literature may have caused the absence of some international studies, as well as masters dissertations and doctoral theses on the examined subject.

\section{Contributions to the area}

The present review allowed to identify and categorize the needs of caregivers to guide the development of transitional care interventions centered at this population and not only at the needs of dependent older people. Future studies must explore nursing interventions in transitional care by focusing on two aspects. The first should be managing care provided to dependent older people, in which nurses must try to act by providing information, planning hospital discharge, carrying out follow-ups, coordinating with community resources, and helping with instrumental care. The second should be managing care to caregivers themselves and, in this case, nursing interventions must be oriented toward the acceptance of the role, emotional support, potential resources, and training to carry out self-care and manage caregivers' health-disease processes.

\section{FINAL CONSIDERATIONS}

Caregivers of older people who are dependent regarding selfcare showed needs in the transition from hospital to home that were grouped into five categories: needs related to this transition; caregivers' self-care needs; health needs; economic needs; and social and community needs. It is important to stress that three subcategories emerged in the first group: information; mastering care; and emotional support and overload prevention.

When planning transitional care, nurses must ensure individualized caregiving of dependent older people and caregivers, to train the latter so they can play their role and to meet their needs. This will help keep adequate health and well-being levels, which in turn will allow continuity of care to dependent older people. It is recommended that health professional establish a positive relationship with caregivers, because this will influence the development of care competences by the latter.

Future studies should examine how nurses carry out the management of care to both dependent older people and their caregivers in the process of transition from hospital to home.

\section{REFERENCES}

1. Melo R, Rua M, Santos C. Support and training of family caregivers: nursing intervention program. Rev Mill. 2018;2(5):73-80. doi: 10.29352/ mill0205.07.00171

2. Alvarez I, Ong M, Abocejo F. Learning needs and quality care among family caregivers and elderly patients of Guadalupe, Cebu City, Central Philippines. Eur Sci J. 2017;13(24):356-76. doi: 10.19044/esj.2017.v13n24p356

3. Brigola A, Luchesi B, Rossetti E, Mioshi E, Inouye K, Pavarini S. Health profile of family caregivers of the elderly and its association with variables of care: a rural study. Rev Bras Geriatr Gerontol. 2017;20(3):409-20. doi: 10.1590/1981-22562017020.160202

4. Everink I, van Haastregt J, Tan F, Schols J, Kempen G. The effectiveness of an integrated care pathway in geriatric rehabilitation among older patients with complex health problems and their informal caregivers: a prospective cohort study. BMC Geriatr. 2018;18(285):1-13. doi: 10.1186/s12877-018-0971-4

5. Cantillo M, Lleopart T, Ezquerra S. Informal care in times of crisis: Analysis from the nursing perspective. Enferm Glob. 2018;50:529-41. doi: 10.6018/eglobal.17.2.297211

6. Bangerter L, Griffin J, Zarit S, Havyer R. Measuring the needs of family caregivers of people with dementia: An assessment of current methodological strategies and key recommendations. J Appl Gerontol. 2019;38(9):1304-18. doi: 10.1177/0733464817705959

7. Hahn-Goldberg S, Jeffs L, Troup A, Kubba R, Okrainec K. "We are doing it together"; The integral role of caregivers in a patients' transition home from the medicine unit. Plos One. 2018;13(5):1-14. doi: 10.1371/journal.pone.0197831

8. Hesselink G, Flink M, Olsson M, Barach P, Dudzik-Urbaniak E, Orrego C, et al. Are patients discharged with care? A qualitative study of perceptions and experiences of patients, family members and care providers. BMJ Qual Saf. 2012; 21(Suppl 1):i39-49. doi:10.1136/ bmjqs-2012-001165

9. Aoun S, Stegmann R, Slatyer S, Hill K, Parsons R, Moorin R, Bronson M, Walsh D, Toye C. Hospital postdischarge intervention trialled with family caregivers of older people in Western Australia: potential translation into practice. BMJ Open. 2018;8(11):1-9. doi: 10.1136/ bmjopen-2018-022747

10. Piersol C, Canton K, Connor S, Giller I, Lipman S, Sager S. Effectiveness of interventions for caregivers of people with alzheimer's disease and related major neurocognitive disorders: A systematic review. Am J Occup Ther. 2017;71(5):7105180020p1-7105180020p10. doi:10.5014/ajot.2017.027581

11. Bierhals C, Santos N, Fengler F, Raubustt K, Forbes D, Paskulin L. Needs of family caregivers in home care for older adults. Rev Latino-Am Enferm. 2017;25:e2870. doi: 10.1590/1518-8345.1511.2870 
12. Ewing G, Austin L, Jones D, Grande G. Who cares for the carers at hospital discharge at the end of life? A qualitative study of current practice in discharge planning and the potential value of using The Carer Support Needs Assessment Tool (CSNAT) Approach. Palliat Med. 2018;32(5):939-49. doi: 10.1177/0269216318756259

13. Hagedoorn E, Paans W, Jaarsma T, Keers J, van der Schans C, Luttik M. Aspects of family caregiving as addressed in planned discussions between nurses, patients with chronic diseases and family caregivers: a qualitative content analysis. BMC Nurs. 2017;16:37. doi: 10.1186/ s12912-017-0231-5

14. Lumini M, Araújo F, Martins T. The role of educational technology in caregiving. Caregiving and Home Care. 2018;11:179- 01. doi: 10.5772/ intechopen.72887

15. Ferreira E, Lourenço O, Costa P, Pinto SC, Gomes C, Oliveira AP. Active Life: a project for a safe hospital-community transition after arthroplasty. Rev Bras Enferm. 2019;72(1):147-53. doi: 10.1590/0034-7167-2018-0615

16. Paniagua DV, Ribeiro MPH, Correia AM, et al. Project K: Training for hospital-community safe transition. Rev. bras. enferm. 2018;71(Suppl 5):2264-71. doi: 10.1590/0034-7167-2018-0190

17. Menezes TMO, Oliveira ALB, Santos LB, Freitas RA, Pedreira LC, Veras SMCB. Hospital transition care for the elderly: an integrative review. Rev Bras Enferm. 2019;72(Suppl-2):294-301. doi: 10.1590/0034-7167-2018-0286

18. Mendes KDS, Silveira RCCP, Galvão CM. Integrative literature review: a research method to incorporate evidence in health care and nursing. Texto Contexto Enferm. 2008;17(4):758-64. doi: 10.1590/S0104-07072008000400018

19. Occelli $\mathrm{P}$, Touzet $\mathrm{S}$, Rabilloud $\mathrm{M}$, et al. Impact of a transition nurse program on the prevention of thirty-day hospital readmissions of elderly patients discharged from short-stay units: study protocol of the PROUST stepped-wedge cluster randomised trial. BMC Geriatr. 2016;16:57. doi: 10.1186/s12877-016-0233-2

20. Bardin L. Análise de Conteúdo. 5a ed. Lisboa: Edições 70; 2011.

21. Allen J, Hutchinson A, Brown R, Livingston P. User experience and care integration in transitional care for older people from hospital to home: a meta-synthesis. Qual Health Res. 2017;27(1):24-36. doi: 10.1177/1049732316658267

22. Alves A, Santana M, Figueiredo N, Andrade N, Slompo N, Pessalacia J. Depression in caregivers of the elderly: Integrative review. Hos Pal Med Int Jnl. 2018;2(6):295-301. doi: 10.15406/hpmij.2018.02.00111

23. Fernandes C, Angelo M. Family caregivers: what do they need? an integrative review. Rev Esc Enferm USP. 2016;50(4):675-82. doi: 10.1590/ s0080-623420160000500019

24. Neves P, Sequeira C, Mar L, Sousa L, Ferre-Grau C. Information needs of family caregivers of dependent individuals. IJCNMH. 2017;4(5):1-6. doi: 10.21035/ijcnmh.2017.4.5

25. Pindus D, Mullis R, Lim L, Wellwood I, Rundell A, Aziz N, Mant J. Stroke survivors' and informal caregivers' experiences of primary care and community healthcare services: systematic review and meta-ethnography. PLoS ONE. 2018;13(2):e0192533. doi: 10.1371/journal.pone.0192533

26. Allen J, Hutchinson A, Brown R, Livingston P. User experience and care for older people transitioning from hospital to home: patients' and carers' perspectives. Health Expect. 2018;21(2):518-27. doi: 10.1111/hex.12646

27. Toye C, Parsons R, Slatyer S, Aoun S, Moorin R, Osseiran-Moisson R, Hill K. Outcomes for family carers of a nurse-delivered hospital discharge intervention for older people (the Further Enabling Care at Home Program): single blind randomised controlled trial. Int J Nurs Stud. 2016;64:32-41. doi: 10.1016/j.ijnurstu.2016.09.012

28. Kynoch K, McArdle A. Information needs and information seeking behaviors of patients and families in acute healthcare settings: a scoping review protocol. JBI Database Syst Rev Implement Rep. 2016;14(10):82-7. doi: 10.11124/JBISRIR-2016-003161

29. Hussain N, Esa A, Mustapha M, Yusoff N, Abdullah M. Associated factors for negatives satisfaction among family caregivers during transitional phase. Int Med J [Internet]. 2016 [cited 2020 Apr 20];23(5):485-9. Available from: https://psycnet.apa.org/record/2017-04038-005

30. Moreno-Cámara S, Palomino-Moral P, Moral-Fernández L, et al. Perceived needs of the family caregivers of people with dementia in a mediterranean setting: a qualitative study. Int J Environ Res Public Health 2019;16:993. doi: 10.3390/ijerph16060993

31. Karimi F, Yaghoubinia F, Keykhah A, Askari H. Investigating the effect of home-based training for family caregivers on the incidence of bedsore in patients with stroke in Ali Ebne Abitaleb Hospital, Zahedan, Iran: a clinical trial study. Med Surg Nurs J. 2018;7(3):e87325. doi: 10.5812/msnj.87325

32. Melo R, Rua M, Santos C. Family caregiver's needs in caring for the dependent person: an integrative literature review. Rev Enferm Ref. 2014;4(2):143-51. doi: 10.12707/RIV14003

33. Baixinho CL, Dixe MA, Henriques MAP. Falls in long-term care institutions for elderly people: protocol validation. Rev Bras Enferm. 2017;70(4):740-6. doi: 10.1590/0034-7167-2017-0109

34. Bom J, Bakx P, Schut F, van Doorslaer E. The impact of informal caregiving for older adults on the health of various types of caregivers: a systematic review. Gerontologist. 2019;59(5):e629-e642. doi: 10.1093/geront/gny137 